\title{
Complete Child Immunisation: A Cluster Analysis of Positive Deviant Regions in Ghana
}

\section{Paul Kyere*}

Department of Health Promotion, Faculty of Psychology, University of Bergen, Christiesgt, Bergen, Norway

"Corresponding author: Department of Health Promotion, Faculty of Psychology, University of Bergen, Christiesgt. 13, 5020 Bergen, Norway, E-mail: busykyere@yahoo.com

Received date: November 08, 2016; Accepted date: January 06, 2017; Published date: January 12, 2017

Copyright: (C 2017 Kyere P, This is an open-access article distributed under the terms of the Creative Commons Attribution License, which permits unrestricted use, distribution, and reproduction in any medium, provided the original author and source are credited.

\begin{abstract}
Background: The Global Vaccine Action Plan sets a target of $90 \%$ child immunisation coverage, a rare achievement in the Global South. Yet two of the poorest of Ghana's 10 regions have accomplished this feat-what can policy-makers and public health authorities learn from these 'positive deviant' regions (PDRs), to inform immunisation strategies elsewhere in the South?

Methods: Using cluster analysis and data from the 2008 Ghana DHS, seven regional-level factors were investigated that might account for differences in immunisation coverage: ethnicity/religion, socioeconomic status, maternal health literacy and decision latitude, use of maternal health facilities, participation in child vaccination campaigns, and availability of community health infrastructure. Rank orders of the 10 regions on these factors were examined for the degree to which the PDRs were similar to each other, and dissimilar to the other eight regions.
\end{abstract}

Results: The PDRs were not similar to each other on any of the regional-level factors. Contrariwise, the PDRs clustered only at the highest stage of agglomeration in the analyses. Thus, the two PDRs do not closely share regional-level characteristics that might explain their PD status, with the study thus failing to differentiate the PDRs from the other regions.

Conclusions: The heterogeneity exhibited by the PDRs is actually reason for optimism, suggesting that even the poorest regions in the South, with disparate characteristics and social situations, can achieve excellent child immunisation coverage. It may be that nation-wide 'one-size-fits-all' government campaigns to encourage child immunisation should be supplemented, or even replaced, by small area, targeted efforts fit-to-purpose and fit-tolocal-conditions.

Keywords: Child immunisation; Positive deviance; Ghana; DHS; Cluster analysis

Abbreviations: PDRs: Positive Deviant Regions; DHS: Demographic and Health Survey.

\section{Background}

The Alma-Ata Declaration recognized immunisation as essential primary health care [1]. During the 1970's, the World Health Organization (WHO) launched the Expanded Programme on Immunization [2,3]. In 1989, WHO recommended that yellow fever vaccine be used in endemic areas. In the 1990's, hepatitis B and Haemophilus influenza type $b$ vaccines were recommended where the disease burden was high [4]. Immunisation has helped to eradicate smallpox [5]. It has lowered the global incidence of polio by $99 \%$ [2]. Apart from safe drinking water, no other public health modality, has led to such major mortality reduction, as has immunisation [6]. Accordingly, immunisation is one of the most cost effective public health investments that the world can make for future generations $[3,7]$.

A report by the Secretariat on WHO-UNICEF Global Immunization Vision and Strategy was a focal point at the $64^{\text {th }}$ world health assembly in 2011. Discussions culminated in the vision for Decade of Vaccines (2011-2020) and the establishment of Global Vaccine Action Plan [5]. The GVAP builds on the success of the GAVI Alliance Strategy [8]. Though immunization has made great impact, many countries in the Global South, including some of Africa's most populous countries-Nigeria, South Africa and Uganda-have coverage rates well below $80 \%[9,10]$. Therefore Reach Every District strategy was devised by WHO to improve stagnating immunization coverage and effectiveness in Africa [11]

Coverage statistics are usually presented at national levels. This masks substantial variation between regions within countries [12]. While achieving complete immunisation coverage is a daunting task, it is possible. For instance, in the face of stiff socio-economic and cultural challenges, two very poor regions in Ghana have achieved complete child immunisation. These regions -Upper West and Brong-Ahafo are the focus of this paper. These regions follow a pattern that has been termed 'positive deviance' (PD), a term first coined by child health researchers:

"Positive deviance is the observation that in most settings a few at risk individuals follow uncommon, beneficial practices and consequently experience better outcomes than their neighbours who share similar risks" [13]. 
The label PD has been criticised as oxymoronic [14], and the alternative term 'optimal outlier' has been proposed [15]. Regardless of how it is labelled, researchers are expanding PD as a scientific arena [16]. Reference in the quote above to 'individuals' is somewhat misleading, since $\mathrm{PD}$ researchers have identified $\mathrm{PD}$ practices in families [17], e.g., infant feeding practices of mothers in rural Vietnam [18]. Recent PD research has moved to the level of health institutions $[19,20]$ and even to organisational development practice [21]. This paper reports PD immunisation research at the regional level, the first such PD analysis at this macro-level. Analysis of immunisation at administrative levels such as regions and districts is of practical value, since government and NGO efforts to improve coverage are mostly implemented at these levels, in additional to national campaigns.

The problem addressed is this: what is it about the two Ghana PDRs(Positive Deviant Regions), compared to the other eight regions (Figure 1), which might explain why and how they have been able to achieve complete child immunisation? The puzzle is deepened by the rurality, deep poverty and remoteness of these regions in the north of Ghana, far from the relatively well-off coastal urban centre of Greater Accra. Are there lessons to be learnt from the success of these PDRs (as has been learnt from PD countries [22]), which might inform enhanced child immunisation strategies in other regions in Ghana, and elsewhere in the Global South?

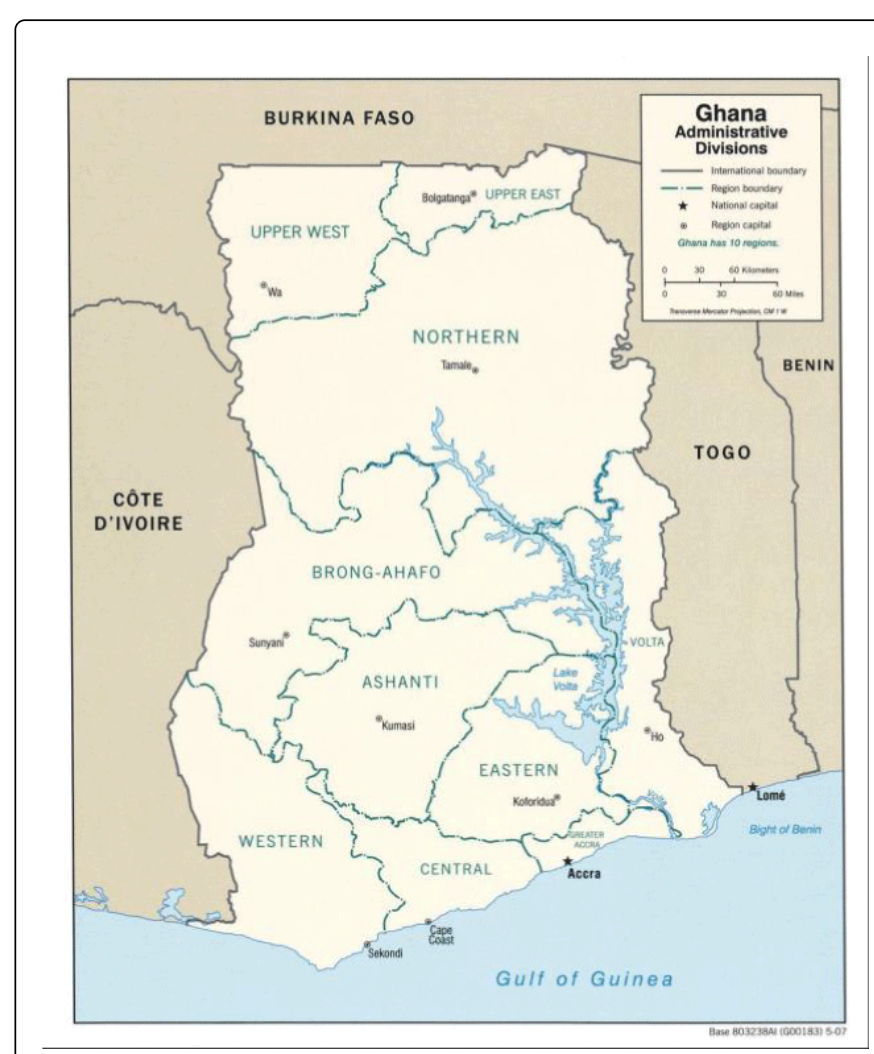

Figure 1: Ghana: the two PDR are Upper West and Brong-Ahafo (www.map.com.com).

Analysis of 126 documents from the global grey literature cited many barriers of incomplete child vaccinations, including poor access to services, unsupportive health staff attitudes, parents' poor practical knowledge of vaccination, and fear of side effects [23]. On the other hand, antenatal care follow-up, being born in a health facility and wealth index, have been associated with vaccination status $[24,25]$. The many socio-demographic factors associated with immunisation coverage in recent research include ethnicity and religion [26], caregiver's education [27], household economic status [28,29], maternal health literacy [29], maternal decision latitude [30], use of maternal and child health facilities [27], participation in vaccination campaigns [31] and urban versus rural living [32]. Few studies investigate why coverage has improved in some settings and not others $[33,34]$ or use positive deviance lens [35]. Substantial inter-regional variation in immunisation coverage within countries [36] gives rise to questions about what regional-level factors might account for immunisation coverage variation. Similar to findings of Haddad et al. [36], Balraj et al. [37] observed that significant inter-district differences in measles immunisation coverage could not be satisfactorily accounted for by the variables studied.

Thus, there are a host of candidate factors that might explain interregional immunisation coverage differences. Yet, there is not much systematic evidence about what policies and vaccination strategies expand immunization coverage [33]. Consequently, this study aimed to address this research question: at the regional level of analysis, do Ghana's two PDRs cluster on one or more of the following factors?

- Ethnicity and religion

- Household socioeconomic status

- Maternal health literacy

- Maternal decision latitude

- Level of participation in child vaccination campaigns

- Community health infrastructure and health status

- Use of maternal and child health facilities

\section{Methods}

The author used the 2008 Ghana Demographic and Health Survey (DHS) data [38]. Mothers provided data on the child's immunisation history, supplemented by information from immunisation cards. The individual-level immunisation data were used to arrive at regionallevel rank order data. The DHS definition of complete immunisation was used: amongst 12-23 months old index children (most recent birth of the female respondent that survived to one year), completion immunisation is defined by BCG, measles and three doses each of DPT and polio vaccine. Immunisation status of all 542 children ages 12-23 as recorded in the DHS dataset was used to calculate regional coverage prevalence of coverage completion (1=highest coverage prevalence, $10=$ lowest).

The regional rank orders for the seven regional-level factors that might impact immunisation coverage was also computed. Using these methods, a dataset consisting entirely of regional-level rank order data was created. No individual level data were analysed except to arrive at the rank order data. The regional rank order data were analysed with hierarchical agglomerative cluster analysis in SPSS 19.0, using Ward's method, and applying squared Euclidean Distance as the similarity measure. The variables were standardised via rank ordering. Lack of dissimilarity from one cluster stage to the next called for clustering to be stopped at the prior stage; this was a subjective, not a quantified procedure [39]. An extended description of the methodology is available elsewhere [40].

Each of the regional-level factors was assessed with several indicators (individual or household level variables aggregated to the regional level: 
Citation: Kyere P (2017) Complete Child Immunisation: A Cluster Analysis of Positive Deviant Regions in Ghana. J Vaccines Vaccin 8: 351. doi:

Page 3 of 7

- Ethnicity and religion: Ethnic group coded Akan or non-Akan religion coded Christian or non-Christian.

- Household-level socioeconomic status: Household assets coded poorest or richest; maternal and paternal educational attainment, each coded none or primary+; maternal and paternal employment (skilled or unskilled).

- Maternal health literacy: exposure to newspapers, radio and television, each coded usually or never; participation in literacy education coded yes or no; awareness of the health issues TB, HIV/ AIDS and STD, each coded yes or no.

- Maternal decision latitude: woman's participation in decisionmaking about her own healthcare, about visiting health facilities; daily/large household purchases, each coded not a big problem or a big problem.

- Use of maternal and child health facilities: woman assisted by medical doctor nurse/midwife during most recent delivery yes/no); place of delivery (health facility or home).
- Participation in public health child vaccination campaigns: Youngest child vaccinated in the Ghana national vaccination campaign of 2006, and in the campaign of 2007, (yes/no).

- Community health infrastructure and health status: each region's prevalence in under-five mortality, in physician/nursing to population coverage, in number of health facilities.

In each of the seven cluster analyses, regional clustering was computed based on the joint clustering effect of all the indicators of the over-ordinate factor (the headings in $\mathrm{i}$ through vii, above).

\section{Results}

The prevalence's data for all indicators are presented in Table 1. The rank order of regions on immunisation was: Brong-Ahafo (91.7\%), Upper-West (90.8\%), Ashanti (85.7\%), Upper-East (84.6\%), Volta (82.5\%), Western (78.7\%), Eastern (76.8\%), Greater-Accra (76.1\%), Central (71.1\%), and Northern (57.77\%).

\begin{tabular}{|c|c|c|c|c|c|c|c|c|c|c|}
\hline \multirow[t]{2}{*}{ Variable } & \multicolumn{10}{|l|}{ Region } \\
\hline & $\begin{array}{l}\text { Brong- } \\
\text { Ahafo }\end{array}$ & Upper-West & Ashanti & Upper-East & Volta & Western & Eastern & $\begin{array}{l}\text { Greater- } \\
\text { Accra }\end{array}$ & Central & Northern \\
\hline $\begin{array}{ll}\text { Complete } & \text { child } \\
\text { immunization (\%) }\end{array}$ & $91.70 \%$ & $90.80 \%$ & $85.70 \%$ & $84.60 \%$ & $82.50 \%$ & $78.70 \%$ & $76.80 \%$ & $76.10 \%$ & $71.10 \%$ & $57.70 \%$ \\
\hline \multicolumn{11}{|c|}{ Prevalence for level of participation in child vaccination campaigns } \\
\hline $\begin{array}{l}\text { Child vaccinated, Nov. } \\
2006 \text { campaign (\%) }\end{array}$ & 4.2 & 3.1 & 3.6 & 0 & 17.5 & 6.3 & 1.8 & 0 & 0 & 3.9 \\
\hline $\begin{array}{l}\text { Child vaccinated, Nov. } \\
2007 \text { campaign (\%) }\end{array}$ & 50 & 21.9 & 24.1 & 2.6 & 37.5 & 25 & 26.8 & 37 & 55.3 & 29.9 \\
\hline \multicolumn{11}{|c|}{ Prevalence for ethnicity and religion } \\
\hline Ethnicity(Akan) (\%) & 60.4 & 0 & 72.6 & 0 & 2.5 & 66.7 & 58.9 & 50 & 89.5 & 6.4 \\
\hline Religion (Christian) (\%) & 75 & 44.6 & 77.4 & 63.2 & 72.5 & 85.4 & 87.5 & 87 & 92.1 & 20.5 \\
\hline Religion (Muslim) (\%) & 18.8 & 40 & 13.1 & 5.3 & 7.5 & 12.5 & 1.8 & 10.9 & 0 & 56.4 \\
\hline \multicolumn{11}{|c|}{ Prevalence for household-level socioeconomic status } \\
\hline $\begin{array}{l}\text { Wealth index (richest) } \\
(\%)\end{array}$ & 52.1 & 23.1 & 67.9 & 17.9 & 42.5 & 52.1 & 55.4 & 89.1 & 71.1 & 16.7 \\
\hline $\begin{array}{l}\text { Maternal } \\
\text { (primary) (\%) }\end{array}$ & 4.2 & 3.1 & 8.3 & 5.1 & 12.5 & 8.3 & 8.9 & 4.3 & 13.2 & 2.6 \\
\hline $\begin{array}{l}\text { Maternal } \\
\text { (higher) (\%) }\end{array}$ & 45.8 & 15.4 & 57.1 & 12.8 & 35 & 47.9 & 64.3 & 73.9 & 42.1 & 9 \\
\hline $\begin{array}{l}\text { Paternal education } \\
\text { (primary) (\%) }\end{array}$ & 14.9 & 11.7 & 7.8 & 20.5 & 8.6 & 7.3 & 8.2 & 2.3 & 14.8 & 5.8 \\
\hline $\begin{array}{l}\text { Paternal } \\
\text { (higher) (\%) }\end{array}$ & \begin{tabular}{|l|}
63.8 \\
\end{tabular} & 26.7 & 81.8 & 25.5 & 71.4 & 80.5 & 89.8 & 90.7 & 70.4 & 14.5 \\
\hline $\begin{array}{l}\text { Maternal employment } \\
\text { (skilled) (\%) }\end{array}$ & 4.2 & 18.8 & 15.5 & 18.4 & 12.5 & 18.8 & 19.6 & 21.7 & 7.9 & 9.1 \\
\hline $\begin{array}{l}\text { Paternal employment } \\
\text { (skilled) (\%) }\end{array}$ & 42.2 & 13.5 & 50 & 25 & 45.9 & 40.9 & 51.1 & 67.4 & 40 & 17.3 \\
\hline $\begin{array}{lr}\text { Maternal } & \text { health } \\
\text { insurance coverage }(\%)\end{array}$ & 58.3 & 46.2 & 35.7 & 63.2 & 23.1 & 33.3 & 51.8 & 26.1 & 15.8 & 25.6 \\
\hline
\end{tabular}


Citation: Kyere P (2017) Complete Child Immunisation: A Cluster Analysis of Positive Deviant Regions in Ghana. J Vaccines Vaccin 8: 351. doi:

Page 4 of 7

\begin{tabular}{|c|c|c|c|c|c|c|c|c|c|c|}
\hline $\begin{array}{l}\text { Money for health care } \\
\text { (\%) }\end{array}$ & 70.8 & 44.6 & 53.6 & 25.5 & 17.9 & 81.3 & 64.3 & 60.9 & 55.3 & 38.5 \\
\hline \multicolumn{11}{|c|}{ Prevalence for maternal health literacy } \\
\hline $\begin{array}{ll}\text { Maternal } & \text { literacy } \\
\text { education (\%) } & \end{array}$ & 4.4 & 10.3 & 5.2 & 16.7 & 0 & 2.3 & 6.1 & 0 & 2.9 & 10.7 \\
\hline Read newspapers (\%) & 6.3 & 9.2 & 7.1 & 7.7 & 5 & 12.5 & 18.2 & 23.9 & 7.9 & 1.3 \\
\hline Listen to radio (\%) & 70.8 & 43.1 & 59.5 & 12.8 & 45 & 54.2 & 52.7 & 67.4 & 50 & 33.3 \\
\hline Watch television (\%) & 52.1 & 23.1 & 56 & 23.1 & 23.1 & 41.7 & 44.6 & 89.1 & 39.5 & 16.7 \\
\hline $\begin{array}{l}\text { Tubercluosis awareness } \\
(\%)\end{array}$ & 91.7 & 80 & 92.9 & 59 & 90 & 81.3 & 94.6 & 87 & 84.2 & 59 \\
\hline $\begin{array}{l}\text { HIVAIDS awareness } \\
(\%)\end{array}$ & 97 & 95.4 & 98.8 & 100 & 95 & 95.8 & 100 & 97.8 & 94.7 & 92.3 \\
\hline STD awareness (\%) & 97.9 & 95.4 & 98.8 & 100 & 95 & 95.8 & 100 & 97.8 & 94.7 & 94.9 \\
\hline \multicolumn{11}{|c|}{ Prevalence for maternal decision latitude } \\
\hline $\begin{array}{l}\text { Woman decides main } \\
\text { purchases }(\%)\end{array}$ & 48.8 & 46.7 & 25 & 73.7 & 34.2 & 39 & 39.1 & 34.9 & 57.1 & 27 \\
\hline $\begin{array}{ll}\begin{array}{l}\text { Decides } \\
\text { purchases (\%) }\end{array} & \text { daily } \\
\end{array}$ & 9.3 & 16.7 & 11.8 & 13.2 & 26.3 & 9.8 & 10.9 & 18.6 & 25 & 10.8 \\
\hline $\begin{array}{l}\text { Maternal decision on } \\
\text { own healthcare (\%) }\end{array}$ & 23.3 & 26.7 & 22.4 & 21.1 & 7.9 & 19.5 & 18.2 & 19 & 22.2 & 21.6 \\
\hline $\begin{array}{l}\text { Can visit health facility } \\
(\%)\end{array}$ & 95.8 & 83.1 & 95.2 & 64.1 & 92.3 & 97.9 & 98.2 & 97.8 & 100 & 83.3 \\
\hline \multicolumn{11}{|c|}{ Prevalence for use of maternal and child health facilities } \\
\hline $\begin{array}{l}\text { Maternal health facilities } \\
\text { use }(\%)\end{array}$ & 77.1 & 81.5 & 59.5 & 84.6 & 70 & 64.6 & 55.4 & 71.9 & 57.9 & 62.3 \\
\hline $\begin{array}{l}\text { Assistance at delivery } \\
\text { by physician (\%) }\end{array}$ & 10.4 & 6.2 & 17.9 & 0 & 2.5 & 6.3 & 5.4 & 30.4 & 5.3 & 1.3 \\
\hline $\begin{array}{l}\text { Assistance at delivery } \\
\text { by nurselmidwife }(\%)\end{array}$ & 66.7 & 38.5 & 63.1 & 28.2 & 40 & 47.9 & 60.7 & 71.7 & 44.7 & 21.8 \\
\hline $\begin{array}{ll}\text { Antenatal } & \text { visits } \\
(6+\text { visits })(\%) & \end{array}$ & 62.5 & 56.9 & 61.9 & 51.3 & 32.5 & 54.2 & 37.5 & 78.3 & 39.5 & 23.1 \\
\hline $\begin{array}{l}\text { Public health centre } \\
\text { delivery }(\%)\end{array}$ & 68.8 & 42.2 & 64.3 & 39.5 & 40 & 46.8 & 60.7 & 69.6 & 34.2 & 24.4 \\
\hline $\begin{array}{l}\text { Private health centre } \\
\text { delivery (\%) }\end{array}$ & 4.2 & 0 & 8.3 & 0 & 5 & 4.3 & 3.6 & 13 & 7.9 & 2.6 \\
\hline \multicolumn{11}{|c|}{ Prevalence for community health infrastructure and health status } \\
\hline $\begin{array}{l}\text { Under five mortality } \\
\text { (Rate) }\end{array}$ & 76 & 142 & 80 & 78 & 50 & 65 & 81 & 50 & 108 & 137 \\
\hline $\begin{array}{l}\text { Distance to health care } \\
\text { services }(\%)\end{array}$ & 87.5 & 53.8 & 76.2 & 28.2 & 66.7 & 70.8 & 73.2 & 80.4 & 73.7 & 47.7 \\
\hline $\begin{array}{l}\text { Physician to population } \\
\text { coverage (Ratio) }\end{array}$ & 22012 & 44736 & 9861 & 33843 & 28490 & 32761 & 17817 & 5177 & 26689 & 70744 \\
\hline $\begin{array}{l}\text { Nursing to population } \\
\text { coverage (Ratio) }\end{array}$ & 1169 & 885 & 1382 & 966 & 909 & 1458 & 973 & 919 & 913 & 1577 \\
\hline
\end{tabular}

Table 1: The prevalence's data for all indicators for the seven regional-level factors. 
Page 5 of 7

Figure 2 shows dendrogram (tree diagram) result for the analysis; dendrogram is a convenient way to summarise great deal of information from cluster analysis. There are at least three ways to interpret the dendrogram results, by (1) changes in cluster dissimilarity from stage to stage (reading left to right); (2) the relative placement in clusters of the two PDRs at each stage, and (3) the clustering pattern with regard to the regions' immunisation completeness rank order without regard to PDRs status.

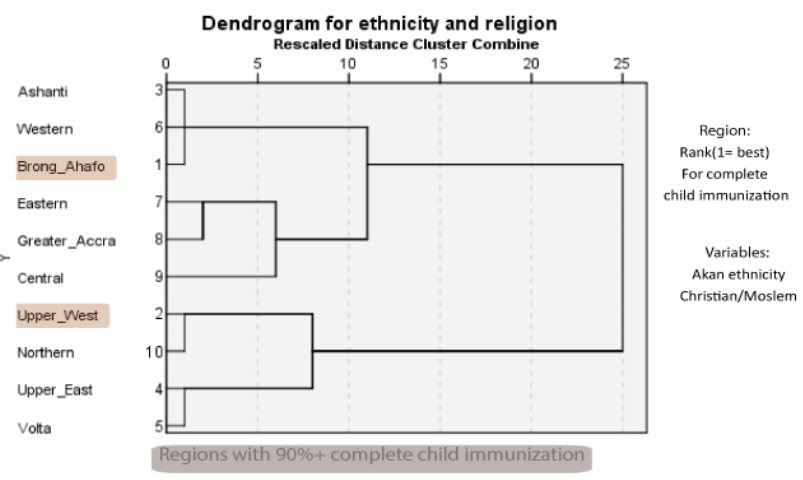

Figure 2: Cluster analysis with regions as cases, dendrogram for religion and ethnicity.

At stage 0 , there are no clusters, as shown in Figure 2. At each subsequent stage of clustering, vertical lines indicate cumulative clustering, and between stages, distances between vertical lines indicate magnitudes of dissimilarity between clusters. The distance measure (rescaled by SPSS from 0 to 25) is one minus the correlation between two clusters, so highly related clusters are indicated by shorter horizontal lines. In Figure 2, Ashanti, Western and Brong-Ahafo regions cluster, and are more strongly inter-correlated on ethnicity and religion than is, for example, the Eastern/Greater Accra cluster. The two PDRs are shown in shaded format (the vertical axis ordinals represent the rank order on immunisation completeness). BrongAhafo and Upper-West do not cluster together at any stage.

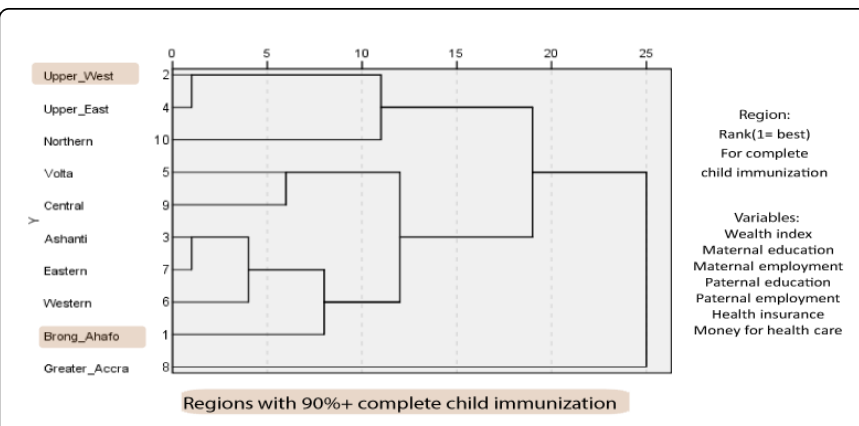

Figure 3: Cluster analysis with regions as cases, dendrogram for household-level socio economic status.

In Figure 3, Upper-West compares most closely with Upper-East and Northern on the socioeconomic status indicators, a similarity with geographic counterparts. The PDRs cluster only at the penultimate stage. Thus, there is less evidence for an association between immunisation completeness and socioeconomic status, compared to immunisation completeness and ethnicity/religion, based on a more dispersed pattern of agglomeration-by-rank. Figure 4 shows similar results for regional-level participation in child immunisation campaigns.

In sum, a noteworthy finding that emerged from comparison of the all the dendrograms from the seven regional-level factors was the heterogeneity of clustering at each stage of analysis.

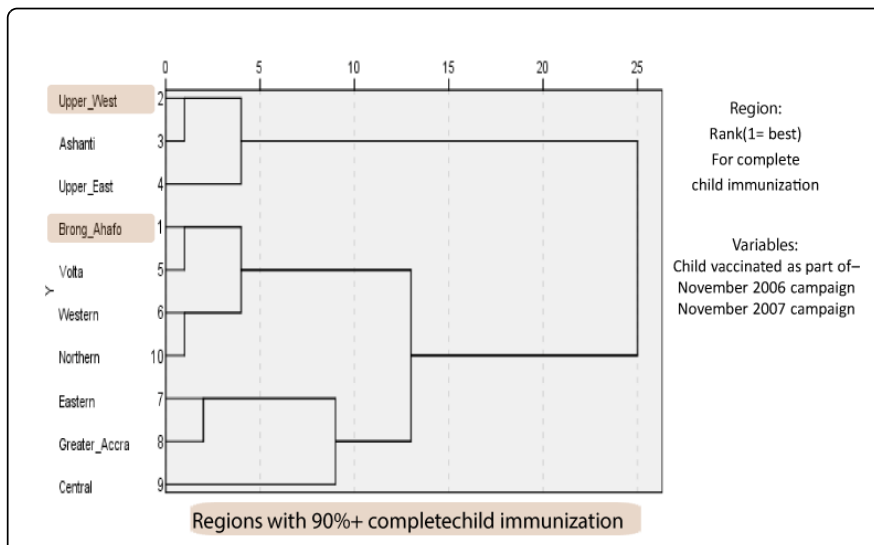

Figure 4: Cluster analysis with regions as cases, dendrogram for participation in child vaccination campaigns.

\section{Discussion}

From the standpoint of the regional-level factors available in this study, the two PDRs do not closely share characteristics that might explain their PD status.

Before discussing these findings and implications, some attention to study limitations is helpful. Two practical limitations in variable selection and in level of analysis were related to the source of the study data. The author used existing data collected by the Ghana Statistical Service [38] in the 2008 DHS of a sample of nationally representative households. These data had only limited coverage of the many factors potentially influencing immunisation coverage. Further, the dataset permits analysis at the individual, regional and national levels, but not the district level within regions, obviating the possibility of districtlevel analyses or generalisation to lower levels of analysis than might have been more informative. Still, as the research question indicates, such generalisation is not attempted in this study. A final caveat concerns the way the multiple indicators of regional-level factors were treated. They were used as indicators of unmeasured constructs. Variability due to each indicator's association with the immunization outcome variable is lost with this method.

The clearest example of how this might be problematic is the factor 'participation in child vaccination campaigns', with two indicators: participation in the 2006 campaign and participation in the 2007 campaign. As the data in Table 1 show, participation rates in the two campaigns varied greatly in all regions. Thus, the low participation rate in the 2006 campaign may have in some way cancelled out the effects of the higher participation rate in the 2007 campaign. An alternative approach might have been to analyse each indicator in its own cluster analysis (No. of analyses=30). Yet this would carry the threat of inflating the probability of finding significant associations, compared to the method used (No. of analyses=7). 
Turning to the discussion of the findings, the 2003 GDHS reported child immunisation coverage of $79.0 \%$ for Brong-Ahafo and $60.3 \%$ for Upper-West [41]. The present analysis of the GDHS data indicates large increases in coverage to over $90 \%$ for these two regions, which are thereby designated as PDRs in the present study. Some kinds of activities and developments during the intervening decade obviously contributed to these positive changes: were they the same factors in both PDRs or different?

Of the seven factors studied, three have a focus that seem more proximal to immunisation coverage (health care services, access and use) and four seem more distal. Starting with most proximal factors, this study did not find that high participation in public health child vaccination campaigns was uniquely common to the PDRs (Figure 4). The 2007 campaign had much better reach than did the 2006 campaign. Interestingly, the number 1 ranked region in the 2007 campaign, Central, was only ranked ninth in immunisation completeness. However important national immunisation campaigns might be, they do not explain why the PDRs have the most exemplary immunisation results. This sheds a bit more light to a small and confusing literature. No other closely comparable studies are available, but two other ecological analyses are available, one at the district level [36] and one at the national level in Sub-Saharan Africa [34]. At the district level in Burkina Faso, Haddad, et al. [36] also found little evidence for the impact of campaigns. Naimoli et al. [34] on the other hand observed that their two PD nations (Ghana and Rwanda) were distinguished from the other countries by their 'robust' implementation of their immunisation programmes. This is intriguing, since at the national level in Ghana there is some evidence for the effectiveness of programmes that include campaigns [34] while in this study, there is no corollary evidence at the regional level in Ghana. However, the Naimoli et al. study did not separate immunisation campaigns from other parts of the Ghana immunisation programme (such as management and financing). The present study had no measures of such functions due to data limitations. The two studies, then, are actually not closely comparable.

Moving to the four factors that are likely more distal in impact on immunisation completeness, religious/ethnic affiliations do not explain why the PDRs are uniquely high on complete child immunisation. This seems a puzzle, since in several prior studies religious affiliation has been shown to be positively associated with children's immunisation status $[26,29]$. Thus, it is prudent to hold open the possibility that anther research methodology, which might preserve the substantial heterogeneity in these data, might illuminate associations with immunisation that are not evident in the present findings.

Moving on, one expects socio-economic status to correlate positively with complete child immunisation [28-29,32]. Yet at the regional level in Ghana, this relationship does not hold. The PDRs ranked poorly on many of the nine indicators of socio-economic status. At the same time, the wealthiest region - Greater Accra ranked only eighth on immunisation completeness. It is almost a truism in public health that the degree of risk factor at one level of analysis cannot necessarily be expected at another level of analysis (the ecological fallacy). This study provides further evidence in support of this cautious position.

Further evidence for the heterogeneity of the two PDRs was obtained in the analyses of maternal health literacy and of maternal decision latitude. This returns the discussion to a theme taken up earlier. The factor indictors were selected due to their face validity as reasonable gauges of the construct under consideration. Different and perhaps more coherent factor structures might have emerged from a quantitative factor analysis. Yet that was not the strategy of this paper, which was restricted by the small analysis $\mathrm{n}$. This is an issue relegated to future exploration, for example using newer DHS data from countries with district-level data and thereby having much larger sample sizes.

\section{Conclusions}

The heterogeneity exhibited by the two PDRs is actually reason for optimism, suggesting that even the poorest regions in the South, with disparate characteristics and social situations, can achieve excellent child immunisation coverage. It may be that nation-wide 'one-size-fitsall' government campaigns to encourage child immunisation should be supplemented, or even replaced, by small area, targeted efforts fit-topurpose and fit-to-local-conditions. To support this, intensive small area studies are needed, to illuminate success factors in areas that have achieved laudable immunisation coverage. This study was undertaken at a regional level of analysis, but sub-regional levels, such as districts, townships or even villages, may provide information that is even more sensitive to local conditions and local success factors. This implies a more resource-intensive approach to achieve complete child immunisation, which may be unescapable if coverage is to be significantly improved. A key conclusion is that locally anchored research that is sensitive to social context should be a priority, focused on the role of local variation in the implementation of more effective immunisation policy. How can immunisation efforts be better fitted to specific communities, how can local demand for vaccination be stimulated, how can innovative management practices improve coverage in hard-to-reach segments in the community, and how can paediatric public health succeed even in the face of unsettled and impoverished local social conditions and resource scarcity [35-40]?.

\section{Acknowledgement}

I thank Prof. Maurice B. Mittelmark for providing the study data. I also wish to thank Ghana Statistical Service and GHS which was responsible for collecting the data. The author was supported by the Norwegian Quota Programme for graduate study at the University of Bergen.

\section{References}

1. Persai D, Panda R, Mathur MR (2015) Self-reported Practices and Attitudes of Community Health Workers (Accredited Social Health Activist) in Tobacco Control - Findings from two states in India. Int J Prev Med 6: 48.

2. Patel MM, Clark AD, Sanderson CF, Tate J, Parashar UD (2012) Removing the age restrictions for rotavirus vaccination: a benefit-risk modeling analysis. PLoS Med 9: e1001330.

3. Ferguson M, Wilkinson DE, Zhou T (2009) WHO meeting on the standardization of HPV assays and the role of the WHO HPV Laboratory Network in supporting vaccine introduction held on 24-25 January 2008, Geneva, Switzerland. Vaccine 27: 337-347.

4. USAID (2009) Immunization Essentials, A Practical Field Guide.

5. Gandhi G, Lydon P, Cornejo S, Brenzel L, Wrobel S, et al. (2013) Projections of costs, financing, and additional resource requirements for low- and lower middle-income country immunization programs over the decade, 2011-2020. Vaccine 31: B137-148.

6. Plotkin S, Orenstein W, Offit P (2008): Vaccines (5th edn.) Saunders, USA.

7. Souza JP, Gülmezoglu AM, Vogel J, Carroli G, Lumbiganon P, et al. (2013) Moving beyond essential interventions for reduction of maternal 
mortality (the WHO Multicountry Survey on Maternal and Newborn Health): a cross-sectional study. Lancet 381: 1747-1755.

8. Oslo (2007) Alleviating system-wide barriers to immunization: GAVI Alliance, Norway.

9. UNICEF (2012) Global Immunization Data.

10. ARISE (2012) Improving the performance of the routine immunization systems in Africa; A case study of the drivers of routine immunization system performance in Cameroon.

11. WHO (2002) The Reach Every District Strategy.

12. International IPS (2007) National Family Health Survey, 2005-06: India: Volume I.

13. Marsh DR, Schroeder DG, Dearden KA, Sternin J, Sternin M (2004) The power of positive deviance. BMJ 329: 1177-1179.

14. Sagarin E (1985) Positive deviance; An oxymoron. Deviant Behavior 6: 169-18.

15. Rupp ME, Huerta T, Cavalieri RJ, Lyden E, Van (2014). Optimum outlier model for potential improvement of environmental cleaning and disinfection. Infection control and hospital epidemiology: Society of Hospital Epidemiologists of America 35: 721-723

16. Spreitzer GM, Sonenshein S (2004) Toward the construct definition of positive deviance. American Behavioral Scientist 47: 828-847.

17. Wray JD (1972) Editorial: Can we learn from successful mothers? J Trop Pediatr Environ Child Health 18: 279.

18. Wollinka O, Keeley E, Burkhalter BR, Bashir N (1997) Health Nutrition Model; Applications in Haiti, Vietnam, and Bangladesh. Arlington.

19. Bradley EH, Curry LA, Ramanadhan S, Rowe L (2009) Research in action: using positive deviance to improve quality of health care Implementation Science 4: 25.

20. Ward MA, Schweizer ML, Polgreen PM, Gupta K (2014) Automated and electronically assisted hand hygiene monitoring systems: A systematic review. American journal of infection control 42: 472-478.

21. Walls JL, Hoffman AJ (2013) Exceptional boards: Environmental experience and positive deviance from institutional norms. Journal of Organizational Behavior 34: 253-271.

22. Hanson CM, Furrer E, Schwalbe N, Berkley S (2013) Prediction of immunisation performance. Lancet 381: 349-350.

23. Favin M, Steinglass R, Fields R, Banerjee K, Sawhney M (2012) Why children are not vaccinated: a review of the grey literature. Int Health 4 : 229-238.

24. Etana B, Deressa W (2012) Factors associated with complete immunization coverage in children aged 12-23 months in Ambo Woreda, Central Ethiopia. BMC Public Health 12: 566.

25. Bosch-Capblanch X, Banerjee K, Burton A (2012) Unvaccinated children in years of increasing coverage: how many and who are they? Evidence from 96 low- and middle-income countries. Trop Med Int Health 17: 697-710.

26. Babalola S (2009) Determinants of the uptake of the full dose of DPT3 in Northern Nigeria: A multilevel analysis. Maternal and Child Health Journal 13: 550-558.
27. Rahman M, Obaida-Nasrin S (2010) Factors affecting acceptance of complete immunization coverage of children under five years in rural Bangladesh. Salud Publica Mex 52: 134-140.

28. Singh B, Singh A, Singh N (2012) Determinants of Immunization in Bosomtwe District of Ashanti Region, Ghana. European Journal of Scientific Research 77: 77-94.

29. Sanou A, Simboro S, Kouyate B, Dugas M (2009) Assessment of factors associated with complete immunization coverage in children aged 12-23 months: a crosssectional study in Nouna district, Burkina Faso. BMC International Health and Human Rights 9: S10.

30. Olorunsaiye CZ (2011) Women's Decision Making Autonomy and Childhood Immunisation Uptake in Nigeria. MPH Thesis, University of North Carolina 2005.

31. Bloom DE, Canning D, Weston M (2015) The Value of Vaccination. World Economics 6.

32. Wiysonge CS, Uthman OA, Ndumbe PM, Hussey GD (2012) Individual and contextual factors associated with low childhood immunisation coverage in sub-Saharan Africa: a multilevel analysis. PLoS One 7: e37905.

33. Gauri V, Khaleghian P (2002) Immunization in developing countries: its political and organizational determinants. World Development 30: 2109-20132.

34. Naimoli JF, Challa S, Schneidman M, Kostermans K (2008) Toward a grounded theory of why some immunization programmes in subSaharan Africa are more successful than others: a descriptive and exploratory assessment in six countries. Health Policy and Planning 23: 379-389.

35. LaFond A, Kanagat N, Steinglass R, Fields R (2015) Drivers of routine immunization coverage improvement in Africa: findings from districtlevel case studies. Health Policy Plan 30: 298-308.

36. Haddad S, Bicaba A, Feletto M, Taminy E (2009) System-level determinants of immunisation coverage disparities among health districts in Burkina Faso: a multiple case study. BMC international health and human rights 9: S15.

37. Balraj V, Mukundan S, Samuel R, John TJ (1993) Factors affecting immunization coverage levels in a district of India. International Journal of Epidemiology 22: 1146-1153.

38. GSS, GHS, ICF Macro (2009) Ghana DHS 2008. Accra.

39. Clatworthy J, Buick D, Hankins M, Weinman J, Horne R (2005) The use and reporting of cluster analysis in health psychology: a review. $\mathrm{Br} \mathrm{J}$ Health Psychol 10: 329-358.

40. Kyere P (2014) Comparative regional-level analysis of complete child immunisation in Ghana. Bergen Open Research Archive.

41. GSS (2004) Noguchi Memorial Institute for Medical Research, ORC Macro: Ghana DHS 2003. Maryland. 